\title{
Development of Diagnostic System for Brain MRI Scanning Based on Robust Information Clustering
}

\author{
Chineke Amaechi Hyacenth1, Aneke Israel Chinagolum², Udeh Chukwuma Callistus ${ }^{3}$ \\ ${ }^{1}$ Computer Engineering Department, Micheal Okpara University of Agriculture Umudike, Abia state, Nigeria \\ ${ }^{2}$ Computer Science Department, Institute of management and Technology Enugu, Enugu state, Nigeria \\ 3ICT Department, Enugu state university of science and technology teaching hospital, Enugu State, Nigeria
}

\begin{abstract}
How to cite this paper: Chineke Amaechi Hyacenth | Aneke Israel Chinagolum | Udeh Chukwuma Callistus "Development of Diagnostic System for Brain MRI Scanning Based on Robust Information Clustering" Published in International Journal of Trend in Scientific Research and Development (ijtsrd), ISSN: 24566470, Volume-3 | Issue-3 , April 2019, pp.865-870, URL: https://www.ijtsrd.c om/papers/ijtsrd23 184.pdf

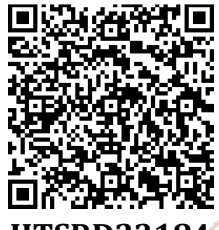
IITSRD23184
\end{abstract}

Copyright (c) 2019 by author(s) and International Journal of Trend in Scientific Research and Development Journal. This is an Open Access article distributed under the terms of the Creative Commons

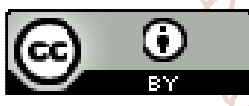
Attribution License (CC BY 4.0) (http://creativecommons.org/licenses/ by $/ 4.0$ )

\section{INTRODUCTION}

Development of diagnostic system for brain MRI scanning based on robust information clustering is the topic of this project. Brain problem has become a severe threat to human lives due to its prevalence. According to the British brain Society, the estimated number of new cases, for all types of brain problem in the world for the year 2017 is over $2,550,110$, and the estimated number of deaths from brain problem is 780,350. In men, brain fake is the most prevalent brain problem which has arisen as a result of smoking Indian hem and taking dangerous drugs. The estimated new cases of men brain problem are 1,550,90, which is the highest number among all types of brain problem (Which is at about $60 \%$.).

\section{Literature Review}

Alzheimer's Disease (AD) is a neurological disorder that mostly affects people over 65 years old and whose incidence rate grows exponentially with age, almost doubling in every 5 years. (Brookmeyer, 2015). Although it has been described for the first time more than 100 years ago, by Alois Alzheimer, only in the last 30 years its causes, symptoms, risk factors and treatment have been intensively investigated. Still, apart from a few exceptions, the factors that trigger the onset of $\mathrm{AD}$ remain unknown (Alzheimer's,2016). It is a progressive disease, meaning that it worsens over time, and for which there is currently no cure, leading eventually to death. The very early stages are often mistakenly confused with the normal process of ageing or linked to stress and it is often characterized by episodic losses of short term memory and difficulty to grasp new ideas. This preclinical stage is also known as Mild Cognitive Impairment (MCI). As the brain damage progresses, other cognitive impairments appear and the disease becomes obvious. In the late stages, individuals are completely dependent on caregivers even for the most basic daily tasks such as eating, bathing or dressing. Moreover, motor skills are affected and patients become more vulnerable to infections. Pneumonia, a lung infection, is one of the most frequent direct causes of death (Wimo, 2016).

Finally, a lot of authors have used different diagnostic approaches on brain; some of these renowned authors are (Samphson,2014) who used optimized method in computerized diagnostic system for brain MRI scanning based on robust information cluster and could only get $32 \%$ achievement. (Donard,2016) used genetic approach in 
computerized diagnostic system for brain MRI scanning based on robust information cluster and achieved at about $41 \%$ efficiency. (Leo, 2015) used proportional integral in the same diagnostic system but could only achieve $38 \%$. This inefficiency in the diagnostic approach has led to the death of many innocent Nigerians. This ugly situation that has led to the death of some Nigerians can be overcome by development of diagnostic system for brain MRI scanning based on robust information clustering using intelligent agent.

\section{Methodology}

To design a membership function that would analyze the symptoms in the brain

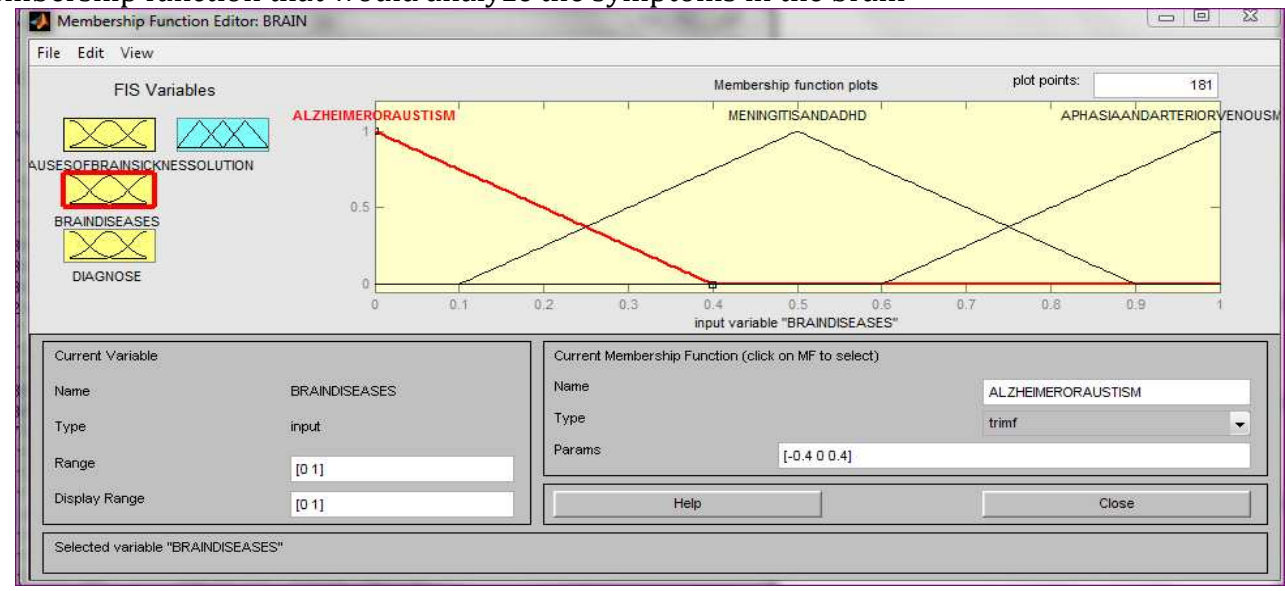

Fig 1 designed membership function that would analyze the symptoms in the brain

Fig 1 shows designed membership function that would analyze the symptoms in the brain. Fig 1 analysis the types of symptoms in the brain.

\section{To design a rule that enhances the diagnosization of the brain symptoms}

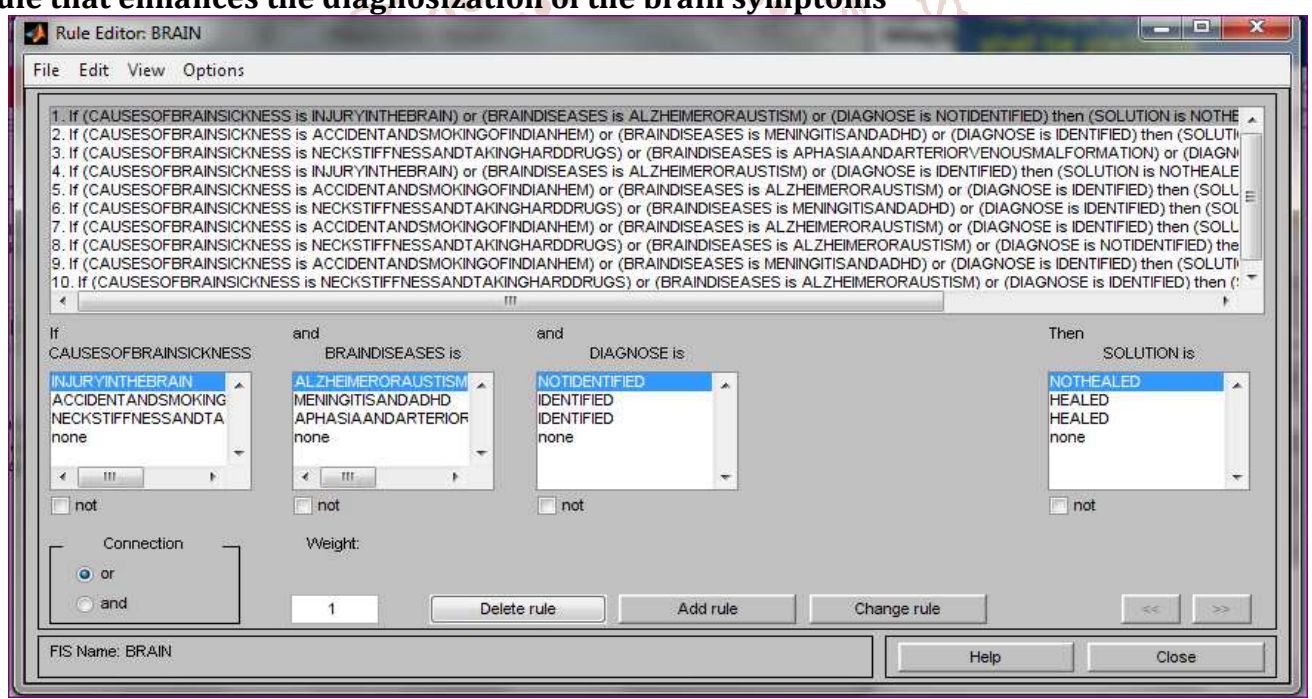

Fig 2 designed rule that enhances the diagnosization of the brain symptoms

Fig 2 shows designed rules that enhance the diagnosization of the brain symptoms. It helps in the identification of the causes of brain problems.

\section{To train these rules in ANN to enhance the efficiency of the diagnosization}

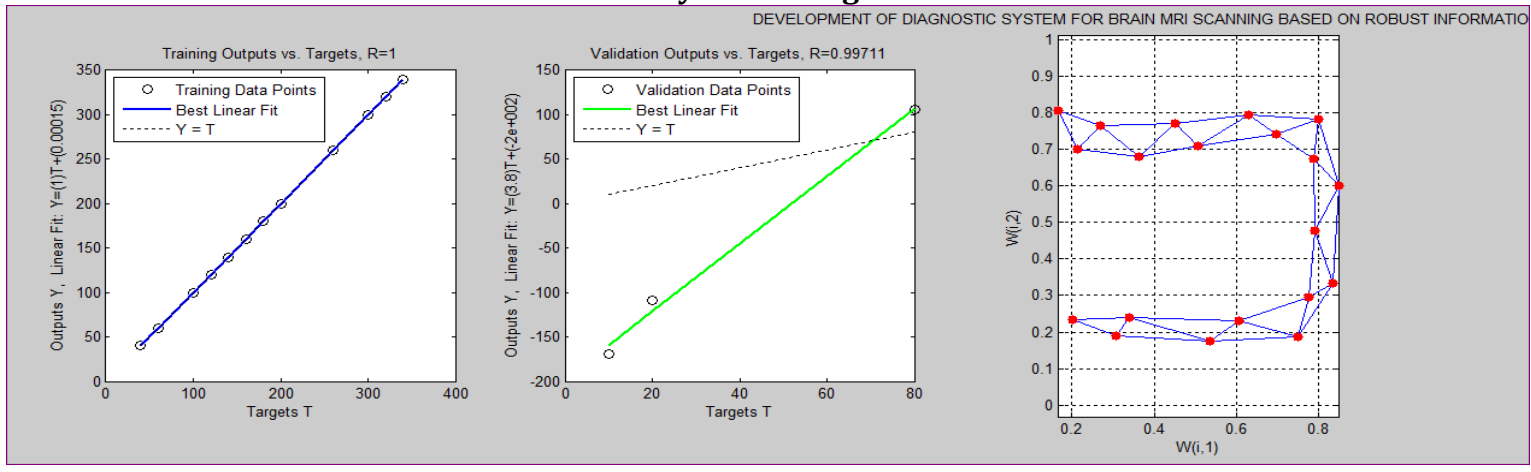

Fig 3 trained rules in ANN to enhance the efficiency of the diagnosization

Fig 3 shows trained rules in ANN to enhance the efficiency of the diagnosization. It is trained to stick strictly to the fast identification of brain symptoms at a lower rate. 
International Journal of Trend in Scientific Research and Development (IJTSRD) @ www.ijtsrd.com eISSN: 2456-6470

To design an intelligent sensor for brain MRI scanning based on robust information clustering.

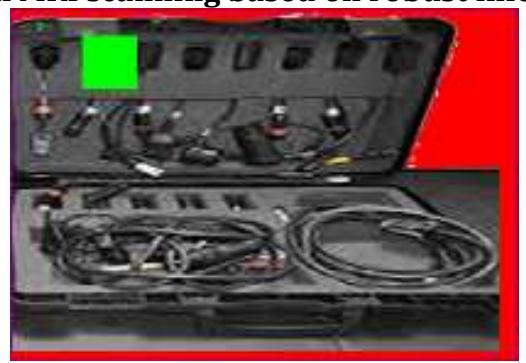

Fig 4 designed intelligent sensor for brain MRI scanning based on robust information clustering

Fig 4 shows designed intelligent sensor for brain MRI scanning based on robust information clustering.

Fig 4 also shows that when the sensor indicates green light, it shows that no brain symptom is observed by the sensor.

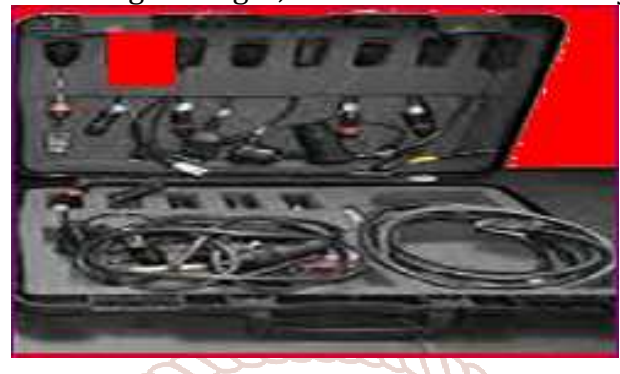

To design a visual basic development of diagnostic system for brain MRI Scanning based on robust information clustering

DEVELOPMENT OF DIAGNOSTIC SYSTEM FOR BRAIN MRI SCANNING BASEO ON ROBUST INFORMATON CUUSTERING

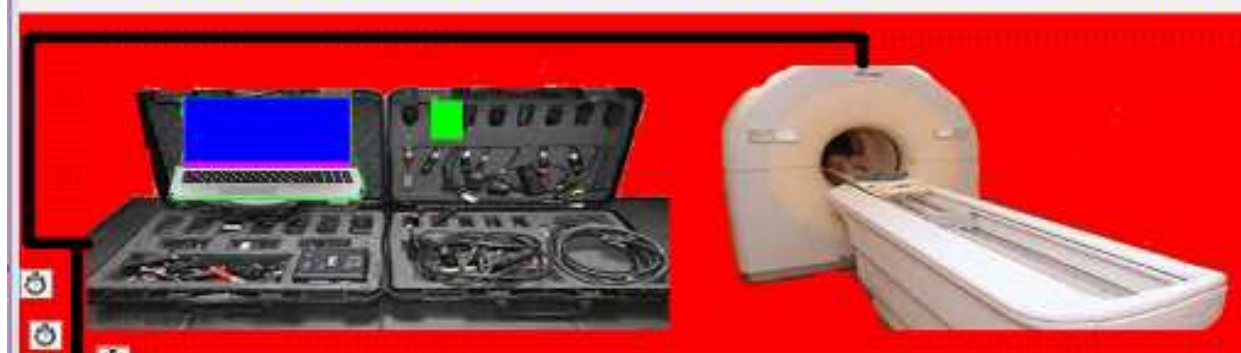

OI

610

83

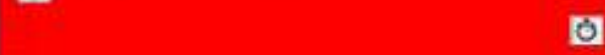

ठ

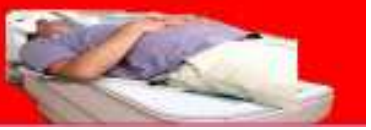

Fig 5 designed visual basic development of diagnostic system for brain MRI Scanning based on robust information clustering

Fig 5 shows designed visual basic development of diagnostic system for brain MRI scanning based on robust information clustering. Fig 5 shows the processing of the brain scanning of an accident victim. Fig 5 also shows green light indicator when it is still in the processing stage.

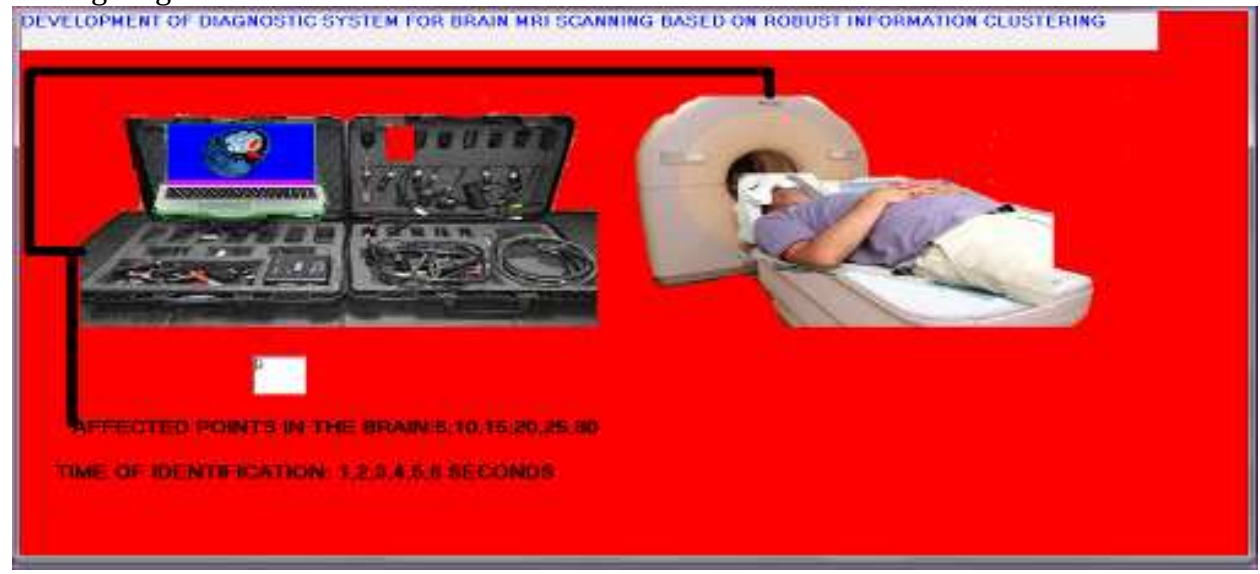

Fig 6 designed visual basic development of diagnostic system for brain MRI Scanning based on robust information clustering 
International Journal of Trend in Scientific Research and Development (IJTSRD) @ www.ijtsrd.com eISSN: 2456-6470

Fig 6 shows designed visual basic development of diagnostic system for brain MRI scanning based on robust information clustering when the machine has identified some wound in the accident victim and the points of its locations.

To design a Simulink model for development diagnostic system for brain MRI scanning without robust information clustering

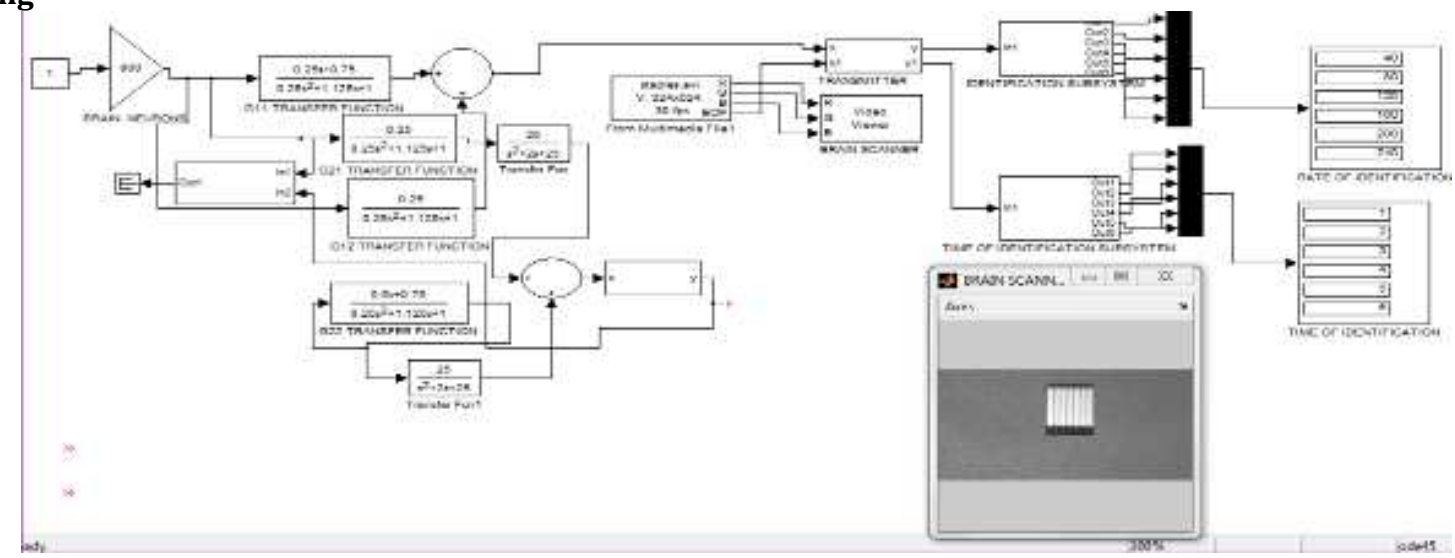

Fig 7 designed Simulink model for development diagnostic system for brain MRI scanning without robust information clustering.

Fig 7 shows designed Simulink model for development diagnostic system for brain MRI scanning without robust information clustering. Table 1 shows the simulated result obtained in designed Simulink model for development diagnostic system for brain MRI scanning without robust information.

To design a Simulink model for development diagnostic system for brain MRI scanning based on robust information clustering

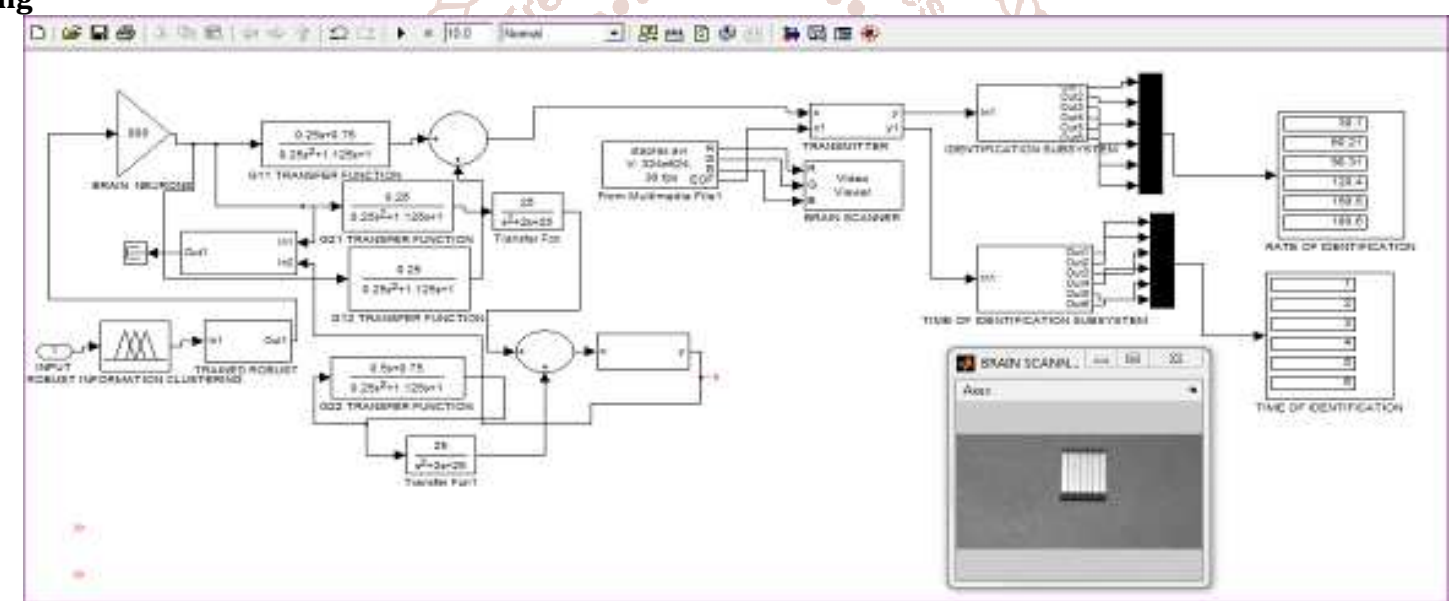

Fig 8 designed Simulink model for development diagnostic system for brain MRI scanning based on robust information clustering

Fig 8 shows designed Simulink model for development diagnostic system for brain MRI scanning based on robust information clustering. Table 2 shows the simulated result gotten when robust information clustering is incorporated in the system.

\section{Result and Analysis}

Table 1 RATE OF BRAIN IDENTIFICATION WITHOUT INTELLIGENT AGENT

\begin{tabular}{|c|c|}
\hline $\begin{array}{c}\text { RATE OF BRAIN IDENTIFICATION } \\
\text { WITHOUT INTELLIGENT AGENT }\end{array}$ & TIME(S) \\
\hline 40 & 1 \\
\hline 80 & 2 \\
\hline 120 & 3 \\
\hline 160 & 4 \\
\hline 200 & 5 \\
\hline 240 & 6 \\
\hline
\end{tabular}


International Journal of Trend in Scientific Research and Development (IJTSRD) @ www.ijtsrd.com eISSN: 2456-6470

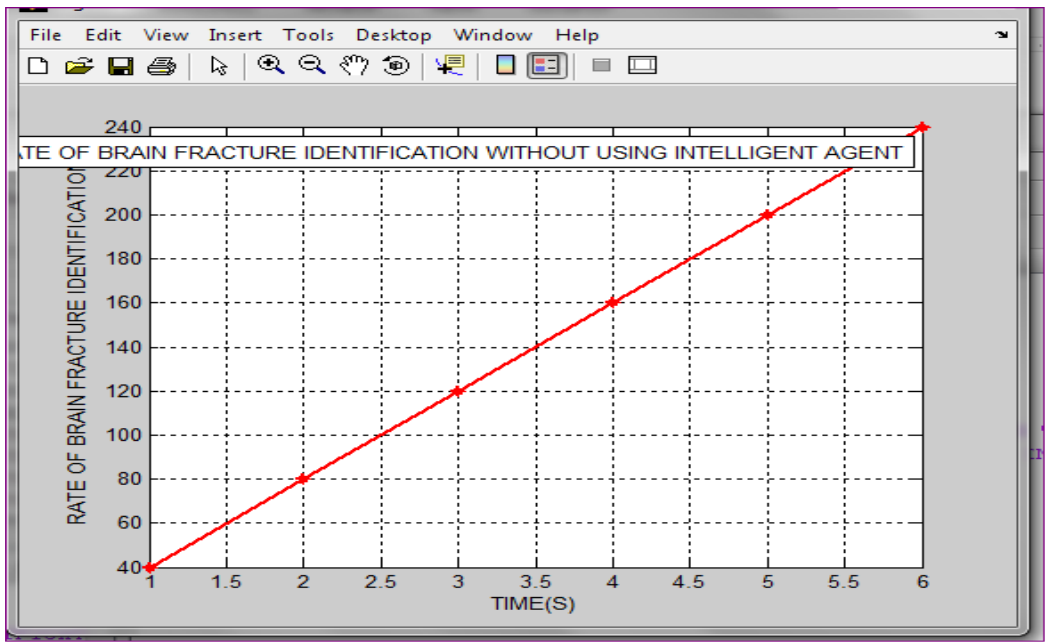

Fig 9 rate of brain identification without robust information (intelligent agent)

Fig 9 shows rate of brain identification without robust information (intelligent agent). The highest rate of identification verse time of its identification is $(240,6)$ while its least of rate of identification verse time occurred at $(40,1)$.

Table 2 Rate of brain identification with intelligent agent

\begin{tabular}{|c|c|}
\hline $\begin{array}{c}\text { RATE OF BRAIN IDENTIFICATION } \\
\text { WITH INTELLIGENT AGENT }\end{array}$ & TIME(S) \\
\hline 30.1 & 1 \\
\hline 60.21 & 2 \\
\hline 90.31 & 3 \\
\hline 120.4 & 4 \\
\hline 150.5 & 5 \\
\hline 180.6 & 6 \\
\hline
\end{tabular}

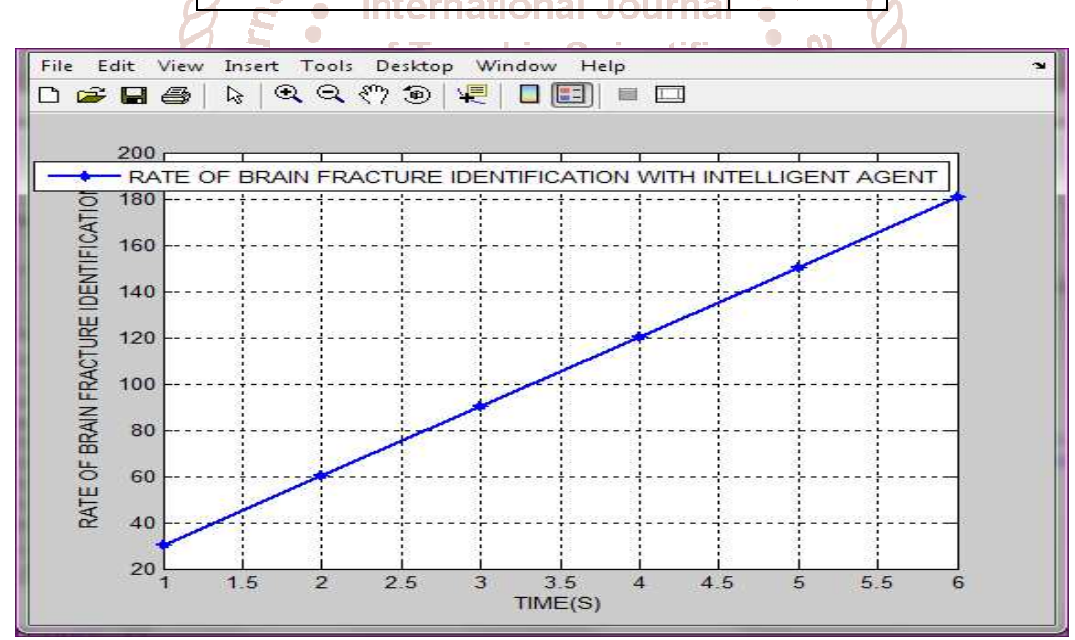

Fig 10 rate of brain identification with robust information (intelligent agent)

Fig 10 shows rate of brain identification with robust information (intelligent agent). Fig 10 shows that the highest rate of identification verse time of its identification occurred at $(180.6,6)$ while the least occurred at $(50.1,1)$.

Table 3 comparing rate of brain identification with and without intelligent agent

\begin{tabular}{|c|c|c|}
\hline $\begin{array}{c}\text { RATE OF BRAIN IDENTIFICATION } \\
\text { WITHOUT INTELLIGENT AGENT }\end{array}$ & $\begin{array}{c}\text { RATE OF BRAIN IDENTIFICATION } \\
\text { WITH INTELLIGENT AGENT }\end{array}$ & TIME(S) \\
\hline 40 & 30.1 & 1 \\
\hline 80 & 60.21 & 2 \\
\hline 120 & 90.31 & 3 \\
\hline 160 & 120.4 & 4 \\
\hline 200 & 150.5 & 5 \\
\hline 240 & 180.6 & 6 \\
\hline
\end{tabular}




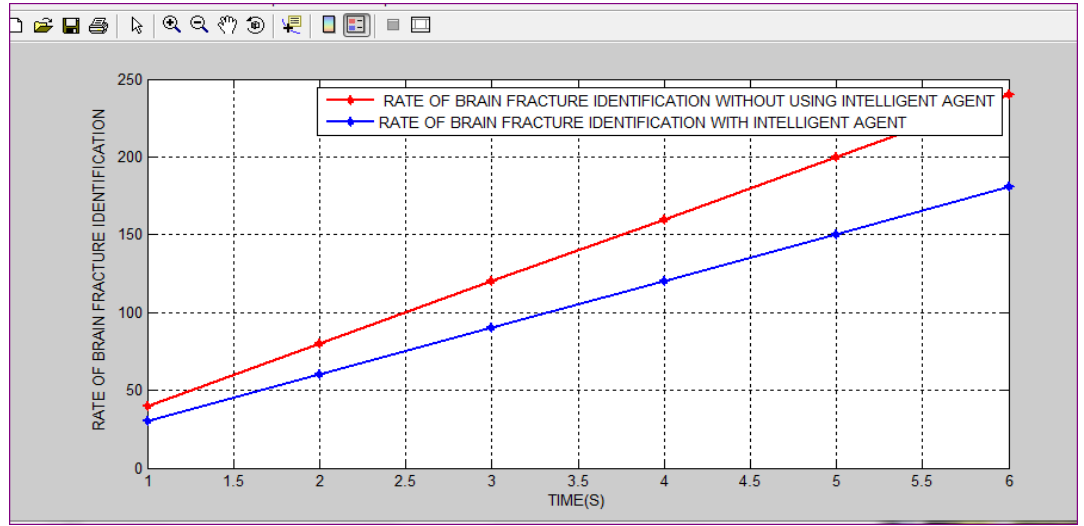

Fig 11 comparing rate of brain identification with and without intelligent agent

Fig 11 shows comparing rate of brain identification with and without robust information (intelligent agent). The result obtained shows that the highest rate of identification verse time when robust information is used is $(180.6,6)$ while the result obtained when it is not used is $(240,6)$. With this result obtained using robust information identifies brain problem faster than when robust information is not used.

\section{Conclusion}

The not identifying brain problem at a faster rate has led to the dying of some innocent souls in our country Nigeria. This unfortunate incidence can be overcome by development of diagnostic system for brain MRI scanning based on robust information clustering. This is done by designing a membership function that would analyze the symptoms in the brain, designing a rule that enhances the diagnosization of the brain symptoms, training these rules in ANN to enhance the efficiency of the diagnosization, designing an intelligent sensor for brain MRI scanning based on robust information clustering, designing a visual basic for development of diagnostic system for brain MRI Scanning based on robust information clustering and designing a Simulink model for development of diagnostic system for brain MRI scanning based on robust information cluster

\section{References}

[1] Alzheimer's J, Factors that trigger the onset of Alzheimer's Disease AD rem 2 016)

[2] Brookmeyer, S. Gray, and C. Kawas, "Projections of Alzheimer's disease in the United States and the public health impact of delaying disease onset," American Journal of Public Health 2015 vol. 88, no. 9, pp. 13371342, 1998.

[3] A. Association, "2012 Alzheimer's disease facts and figures," Alzheimer's and Dementia: The Journal of the Alzheimer's Association, vol. 8, no. 2, pp. 131-168, 2012.

[4] C. P. Ferri, R. Sousa, E. Albanense, W. s. Ribeiro, and M. Honyashiki, "World Alzheimer Report 2009," 2009.

[5] Donard D information technology on clustering,2016)

[6] Samphson y Diagnostic approach on brain ,2014)

[7] LeoMRI scanning based on robust information cluste,2015)

[8] Wimo and M. Prince, "World Alzheimer Report 2010: The global economic impact of dementia," September 2016 